\title{
SEPARATION OF GAS MIXTURE BY MOVING-WALLS THERMAL DIFFUSION COLUMN
}

TAKAO KOKUGAN*, Hitoshi YOSHIDA AND MASARU SHIMIZU

Department of Chemical Engineering, Tokyo University of Agriculture and Technology, Tokyo, 184

By moving the walls of a thermal diffusion column and applying a linear fluid shear, improvement in separation of mixture was tried theoretically and numerically. Ramser ${ }^{3)}$ derived a theory of movingwalls thermal diffusion and obtained steady and unsteady state solutions for a batch type flat plate thermal diffusion column. He found from numerical solutions that fluid motion through externally applied linear shear resulted in a faster rate of approach to equilibrium. $\mathrm{Yeh}^{5)}$ and $\mathrm{Tsai}^{6}{ }^{6}$ developed transport equations for batch and continuous flow thermal diffusion columns and pointed out that the separation by thermal diffusion column employed with moving walls was greater than one with stationary walls (ClusiusDickel column), that is, moving-walls effect. In the present paper moving-walls effect and the relation between the improved separation and operating conditions are generalized. A method for solving simply and graphically the optimal moving walls velocity and the maximum separation is proposed and illustrated by an example.

\section{Description of Moving-Walls Effect}

The hot wall of a parallel plates thermal diffusion column which is inclined by an angle of $\theta$ degrees from the vertical is caused to move with constant velocity $+V$, and the cold wall with opposite equal velocity $-V$. The velocity distribution of fluid in the column is

$$
v=\frac{\rho g \cos \theta \beta_{T} \Delta T w^{2}}{12 \mu}\left[\left(\frac{x}{w}\right)-\left(\frac{x}{w}\right)^{3}\right]+V\left(\frac{x}{w}\right)
$$

Eq. (1) is determined so as to satisfy $B \int_{-w}^{w} \rho v d x=0$ for batch operation. When the end effects are ignored, then the transport equation is given as follows.

$$
\begin{aligned}
\tau= & \left(H_{F}+H_{1} \cdot V\right) \cdot C(1-C) \\
& -\left(K_{C F}+K_{D F}+K_{1} \cdot V+K_{2} \cdot V^{2}\right) \cdot \frac{d C}{d z}+\sigma C
\end{aligned}
$$

where

Received March 5, 1976.

Presented at the 40th Annual Meeting of The Soc. of Chem. Engrs., Japan, at Nagoya, April 1975.

$$
\begin{aligned}
H_{F} & =\left\{\alpha_{T} \rho^{2} g \beta_{T} B(\Delta T)^{2} / 6 ! \mu \bar{T}\right\} \cdot \cos \theta(2 w)^{3} \\
& =H_{F}^{*} \cos \theta \cdot(2 w)^{3} \\
K_{C F} & =\left\{\rho^{3} g^{2} \beta_{T}^{2} B(\Delta T)^{2} / 9 ! D \mu^{2}\right\} \cdot \cos ^{2} \theta(2 w)^{7} \\
& =K_{C F}^{*} \cos ^{2} \theta \cdot(2 w)^{7} \\
K_{D F} & =\rho D B(2 w)=K_{D F}^{*} \cdot(2 w) \\
H_{1} & =\left\{\alpha_{T} \rho B \Delta T / 3 ! T\right\}(2 w)=H_{1}^{*}(2 w) \\
K_{1} & =\left\{\rho^{2} g \beta_{T} B \Delta T / 1680 D \mu\right\} \cos \theta \cdot(2 w)^{5} \\
& =K_{1}^{*} \cos \theta(2 w)^{5} \\
K_{2} & =(\rho B / 30 D) \cdot(2 w)^{3}=K_{2}^{*}(2 w)^{3}
\end{aligned}
$$

Let us compare the separation of a moving-walls column with that of stationary walls column (ClusiusDickel column). Separation of batch type column $\left(\tau=\sigma_{E} \cdot C_{E}=0, \sigma=0\right)$ are considered. For stationary walls column $(V=0)$, separation factor $(q)$ results in Eq. (5), using the boundary conditions below:

$$
\begin{aligned}
& C=C_{s} \quad \text { at } \quad z=0 \\
& \left.C=C_{E} \quad \text { at } \quad z=L_{T}\right\} \\
& \ln q=H_{F}^{*} \cos \theta(2 w)^{2} L_{T} /\left\{K_{C F}^{*} \cos ^{2} \theta(2 w)^{6}+K_{D F}^{*}\right\}
\end{aligned}
$$

With respect to distance between walls $(2 w)$, for stationary walls column maximum separation factor $q_{\max , v=0}$ is given when Eq. (6) is satisfied ${ }^{2)}$.

$P\left(\equiv K_{D F} / K_{C F}\right)=2 \quad$ or $\quad 2 w=\left(K_{D F}^{*} / 2 K_{C F}^{*} \cos ^{2} \theta\right)^{1 / 6}$

The ratio of separation factor of moving-walls column to $q_{\max , v=\theta=0}$ is

$$
\begin{aligned}
& Y \equiv \ln q / \ln q_{\mathrm{max}, v=\theta=0} \\
& =\left[\frac{H_{F}^{*}(2 w)^{2} \cdot \cos \theta+H_{1}^{*} \cdot V}{H_{F}^{*} \cdot(2 w)_{\text {best }}^{2}}\right] / \\
& {\left[\frac{K_{C F}^{*} \cos ^{2} \theta(2 w)^{6}+K_{D F}^{*}+K_{1}^{*} \cos \theta(2 w)^{4} \cdot V+K_{2}^{*}(2 w)^{2} \cdot V^{2}}{K_{C F}^{*} \cdot(2 w)_{\text {best }}^{6}+K_{D F}^{*}}\right]}
\end{aligned}
$$

where $(2 w)_{\text {best }}$ is the distance between walls which satisfies Eq. (6) at $\theta=0$.

The following relations are obtained from Eq. (3) for all $2 w$ and inclining angle $\theta$.

$$
\left.\begin{array}{rl}
H_{1} / H_{F} & =H_{1}^{*} /\left\{H_{F}^{*} \cos \theta(2 w)^{2}\right\} \\
K_{1} / K_{C F} & =K_{1}^{*} /\left\{K_{C F}^{*} \cos \theta(2 w)^{2}\right\}=1.8\left(H_{1} / H_{F}\right) \\
K_{2} / K_{C F} & =K_{2}^{*} /\left\{K_{C F}^{*} \cos ^{2} \theta(2 w)^{4}\right\}=0.84\left(H_{1} / H_{F}\right)^{2}
\end{array}\right\}
$$

Taking account of Eqs. (6) and (8), Eq. (7) results in 

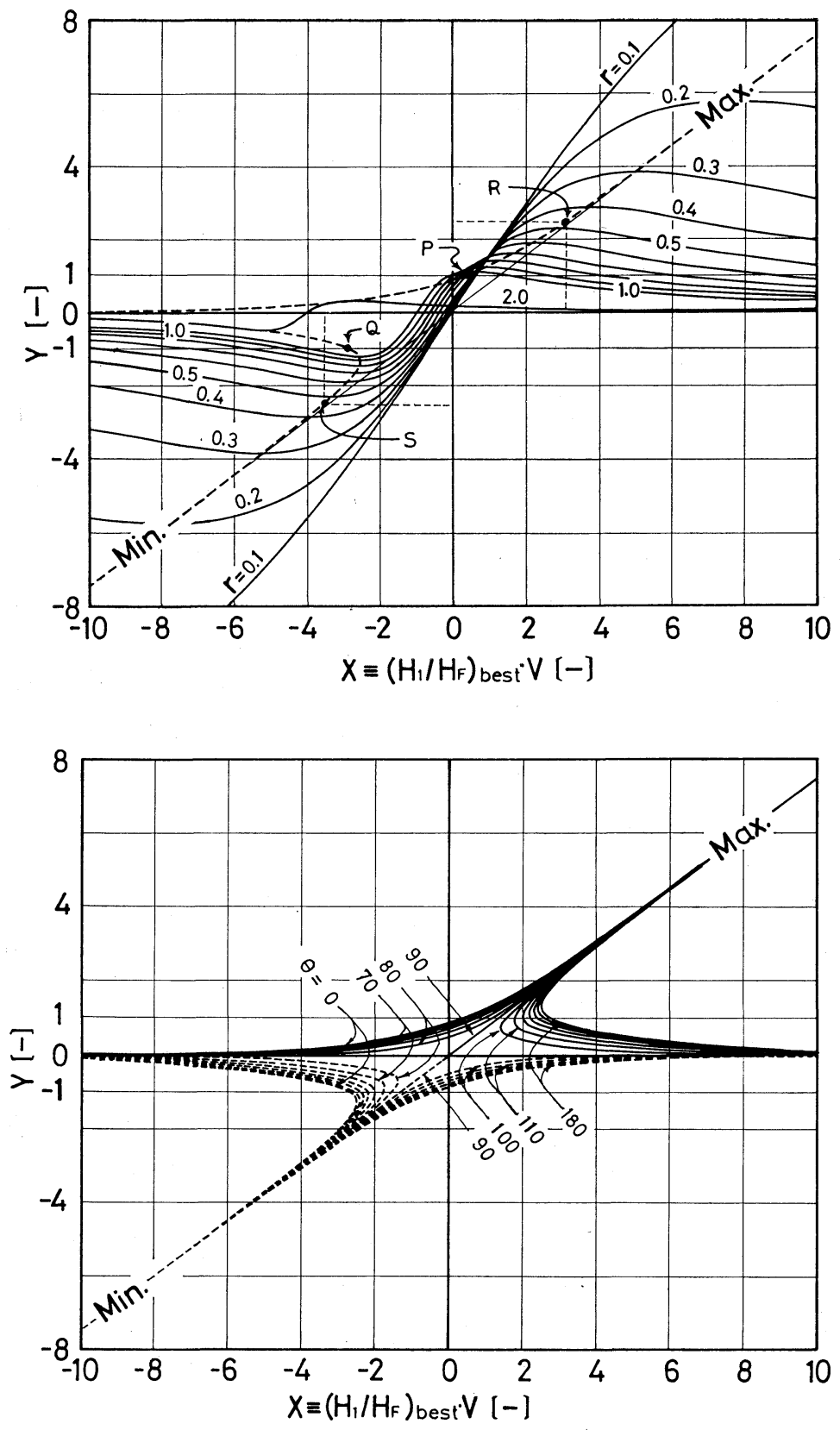

Fig. 1 The relation between dimensionless moving-walls velocity and relative separation factor for $\theta=0$
Fig. 2 The effect of inclining angle of column on relative separation factor

$$
\begin{aligned}
Y= & 3\left(r^{2} \cos \theta+X\right) /\left(r^{6} \cos ^{2} \theta+2+1.8 r^{4} \cos \theta \cdot X\right. \\
& \left.+0.84 r^{2} X^{2}\right)
\end{aligned}
$$

where

$$
\begin{aligned}
& r=2 w /(2 w)_{\text {best }} \text { or } P=2 / r^{6} \\
& X=\left(H_{1} / H_{F}\right)_{\text {best }} \cdot V
\end{aligned}
$$

$X$ is dimensionless moving walls velocity. Maximum and minimum values for constant inclining angle, $f\left(X_{\text {opt }} Y_{\mathrm{max}}\right)$ and $f\left(X_{\mathrm{opt}}^{\prime}, Y_{\mathrm{min}}\right)$, are expressed as follows. $X_{\text {opt(t), opti-) }}=-r^{2} \cos \theta \pm \sqrt{\left(2+0.04 r^{2} \cos ^{2} \theta\right) / 0.84 r^{2}}$ $Y_{\max (+), \min (-)}$

$$
\left.=\frac{ \pm 3 \sqrt{\left(2+0.04 r^{6} \cos ^{2} \theta\right) / 0.84 r^{2}}}{4+0.08 r^{6} \cos ^{2} \theta \pm 0.12 r^{4} \cos \theta \sqrt{\frac{\left(2+0.04 r^{6} \cos ^{2} \theta\right)}{0.84 r^{2}}}}\right\}
$$

Especially for $r<0.2$,

$$
Y=(3 / 4) \cdot X
$$

The relation between separation and moving-walls velocity for $\theta=0$ is shown in Fig. 1, taking $r$ as a parameter. The moving-walls effect is defined that separation is improved over that of the column with $(2 w)_{\text {best }} \ln q_{\text {max } v=\theta=0}$. In Fig. 1 points of $P$ and $Q$ represent the intersections of maximum value and $Y=1$ and minimum value and $Y=-1$, respectively. $P$ and $Q$ correspond to $r=1.08(P=1.28)$ and $r=1.22$ $(P=0.451)$. The $r$ at $Q$ is larger than one at $\mathrm{P}$, but also the optimal velocity is has to be large. For $r<1.22$ or $P>0.451$ the separation can be improved by operating at the optimal velocity. The relation of maximum and minimum values is shown in Fig. 2. 
The separations are symmetrical with respect to $\theta=90$ and $X=0$. As the inclining effect exists at $P<1$ or $r>1.12^{2}$, it is expected that moving-walls effect is multiplied by inclining a column for the range of $1.12<r<1.22$, but the multiplication is small.

\section{Illustration}

By moving-walls column a helium-argon gas mixture (50 mass $\%$ ) is separated under batch operation and under the following conditions.

$$
T_{H}=200^{\circ} \mathrm{C}, \quad T_{C}=25^{\circ} \mathrm{C}, \quad B=10 \mathrm{~cm}
$$

and

$$
L_{T}=100 \mathrm{~cm} \text {. }
$$

a) Calculate $(2 w)_{\text {best }}$ and $q_{\max , v=0}$ at stationary walls column.

b) Calculate $q$ at stationary walls column, the optimal moving walls velocity $\left(V_{\text {opt }}\right)$ and the separation factor $\left(Y_{\max }\right)$ for $2 w=0.5 \mathrm{~cm}$.

c) Calculate $q_{v=\theta=0}, V_{\mathrm{opt}}$ and $Y_{\max }$ for $2 w=2.0 \mathrm{~cm}$.

\section{Solutions and Consideration}

Physical properties and the coefficients defined by Eq. (3) for a helium-argon gas mixture (50 mass \%) are listed in Table 1.

a) From Eq. (6), $(2 w)_{\text {best }}=1.068 \mathrm{~cm}$. The stationary walls column coefficients $H_{H}, K_{C F}$ and $K_{D F}$ for $2 w=1.07 \mathrm{~cm}$ are listed in the first column of Table 2. The maximum separation factor $\ln q_{\max , v=\theta=0}=$ 10.6 .

b) The stationary walls column coefficients for $2 w=0.5 \mathrm{~cm}$ are listed in the second column of Table 2. $q$ is $\ln q=3.46 . \quad r\left(=2 w /(2 w)_{\text {best }}\right)$ is $0.5 / 1.07=$ $0.468<1.22$, therefore moving-walls effect is expected. The optimal velocities $\left(X_{\mathrm{opt}}, X_{\mathrm{opt}}^{\prime}\right)$ and the maximum and minimum separation factor ratios $\left(Y_{\max }, Y_{\min }\right)$ can be calculated from Eq. (12). (refer to Fig. 1)

$$
\begin{aligned}
& R:\left(X_{\mathrm{opt}}, Y_{\max }\right)=(3.08,2.46), \\
& S:\left(X_{\mathrm{opt}}, Y_{\mathrm{min}}\right)=(-3.52,-2.48)
\end{aligned}
$$

The "minus" sign of $Y$ can be regarded as "plus" from the definition of separation factor, if stripping section takes the place of enriching. The "minus" sign of $X$ corresponds to the case whese the hot wall is moved downwards. Separation operation is prefered with "minus" over "plus" because of $Y_{\max }<$ $\left|Y_{\min }\right|$, but the velocity must be made to be large. $\left(H_{1} / H_{F}\right)_{\text {best }}$ is $0.2587 \mathrm{sec} / \mathrm{cm}$, therefore dimensional optimal velocity $V_{\text {opt }}$ is $V_{\text {opt }}=X_{\text {opt }} /\left(H_{1} / H_{F}\right)_{\text {best }}=-13.6$ $\mathrm{cm} / \mathrm{sec}$. $\quad \ln q$ for $2 w=0.5 \mathrm{~cm}$ and $V=-13.6 \mathrm{~cm} / \mathrm{sec}$ is 2.48 times as large as for statinary walls column and $2 w=$ best distance and 7.59 times $(=26.2 / 3.46)$ for stationary walls column and $2 w=0.5 \mathrm{~cm}$ (same distance).

c) The stationary walls column coefficients for
Table 1 Physical properties and coefficients (helium-argon 50 mass \%, $1 \mathrm{~atm}$ )

\begin{tabular}{ll}
\multicolumn{1}{c}{ Physical properties ${ }^{1,4)}$} & Coefficients defined by Eq. (3) \\
\hline$\rho=0.2403 \times 10^{-3}\left[\mathrm{~g} / \mathrm{cm}^{3}\right]$ & $H_{F}^{*}=0.3880 \times 10^{-3}\left[\mathrm{~g} / \mathrm{sec} \cdot \mathrm{cm}^{3}\right]$ \\
$\mu=0.2628 \times 10^{-3}[\mathrm{~g} / \mathrm{cm} \cdot \mathrm{sec}]$ & $H_{1}^{*}=0.1145 \times 10^{-3}\left[\mathrm{~g} / \mathrm{cm}^{2}\right]$ \\
$\beta_{T}=0.2593 \times 10^{-2}\left[1 /{ }^{\circ} \mathrm{K}\right]$ & $K_{C F}^{*}=0.9420 \times 10^{-3}\left[\mathrm{~g} / \mathrm{sec} \cdot \mathrm{cm}^{6}\right]$ \\
$D=1.162\left[\mathrm{~cm}^{2} / \mathrm{sec}\right]$ & $K_{D F}^{*}=0.2792 \times 10^{-2}[\mathrm{~g} / \mathrm{sec}]$ \\
$\alpha_{T}=0.63[-]$ & $K_{1}^{*}=0.5001 \times 10^{-3}\left[\mathrm{~g} / \mathrm{cm}^{5}\right]$ \\
& $K_{2}^{*}=0.6893 \times 10^{-4}\left[\mathrm{~g} \cdot \mathrm{sec} / \mathrm{cm}^{4}\right]$ \\
\hline
\end{tabular}

Table 2 Coefficients and solutions

\begin{tabular}{lllll}
\multicolumn{1}{c}{ Solution } & \multicolumn{1}{c}{$\mathrm{a}$} & \multicolumn{1}{c}{$\mathrm{b}$} & $\mathrm{c}$ \\
\hline $2 w$ & {$[\mathrm{~cm}]$} & 1.068 & 0.5 & 2.0 \\
$H_{F} \times 10^{3}$ & {$[\mathrm{~g} / \mathrm{sec}]$} & 0.4725 & 0.04849 & 3.103 \\
$K_{C F} \times 10^{3}$ & {$[\mathrm{~g} \cdot \mathrm{cm} / \mathrm{sec}]$} & 1.493 & 0.00736 & 120.5 \\
$K_{D F} \times 10^{3}$ & {$[\mathrm{~g} \cdot \mathrm{cm} / \mathrm{sec}]$} & 2.983 & 1.396 & 5.584 \\
$\ln q_{v=\theta=0}$ & {$[-]$} & 10.56 & 3.455 & 2.459 \\
$P$ & {$[-]$} & 1.997 & 189.7 & 0.04631 \\
$r$ & {$[-]$} & 1.0 & 0.4682 & 1.873 \\
$X_{\text {opt }}$ & {$[-]$} & 0.5584 & 3.077 & \\
$Y_{\max }$ & {$[-]$} & 1.096 & 2.460 & \\
$\ln q_{\max }$ & {$[-]$} & 11.57 & 25.98 & \\
$V_{\text {opt }}$ & {$[\mathrm{cm} / \mathrm{sec}]$} & 2.158 & 11.89 & \\
$X_{\mathrm{opt}}^{\prime}$ & {$[-]$} & -2.558 & -3.515 & \\
$Y_{\min }$ & {$[-]$} & -1.201 & -2.483 & \\
$\ln q_{\min }$ & {$[-]$} & 12.68 & 26.23 & \\
$V_{\mathrm{opt}}^{\prime}$ & {$[\mathrm{cm} / \mathrm{sec}]$} & -9.883 & -13.58 & \\
\hline
\end{tabular}

$2 w=2.0 \mathrm{~cm}$ are listed in the third column of Table 2. The moving-walls effect does not exist because $r=2.0 / 1.07=1.87>1.22$.

$$
\begin{aligned}
& \text { Nomenclature } \\
& B \quad=\text { column width } \quad[\mathrm{cm}] \\
& C \quad=\text { mass fraction of lighter component } \quad[-] \\
& H \quad=\text { column coefficient } \quad(\mathrm{g} / \mathrm{sec}) \\
& K=\text { column coefficient } \quad[\mathrm{g} \cdot \mathrm{cm} / \mathrm{sec}] \\
& L_{T} \quad=\text { total column length } \quad \text { [cm] } \\
& P \quad=\text { parameter }=K_{D F} / K_{C F} \\
& q \quad=\text { separation factor }=\left[C_{E} /\left(1-C_{E}\right)\right] /\left[C_{S} /\left(1-C_{S}\right)\right] \\
& r \quad=2 w /(2 w)_{\text {best }} \\
& T_{C}, T_{H}=\text { cold and hot wall temperatures } \quad\left[{ }^{\circ} \mathrm{C}\right] \\
& V \quad=\text { moving-walls velocity } \quad[\mathrm{cm} / \mathrm{sec}] \\
& 2 w \quad=\text { distance between walls } \quad[\mathrm{cm}] \\
& \begin{aligned}
X \quad & \text { dimensionless moving-walls velocity } \\
& =\left(H_{1} / H_{F}\right)_{\text {best }} \cdot V
\end{aligned} \\
& x=\text { axis normal to the plates } \quad[\mathrm{cm}] \\
& Y \quad=\text { relative separation factor defined by Eq. (7) [-] } \\
& \alpha_{T} \quad=\text { thermal diffusion factor } \quad[-] \\
& \left.\begin{array}{rl}
\beta_{T} \quad & \text { thermal expansion coefficient } \\
& =-(\partial \rho / \partial T) / \rho
\end{array}\right] \\
& \theta \quad=\text { inclining angle of column from the vertical [deg.] } \\
& \begin{array}{lll}
\sigma & =\text { product flow rate } \quad[\mathrm{g} / \mathrm{sec}]
\end{array}
\end{aligned}
$$

\section{Literature Cited}

1) Kokugan, T., N. Ishizaka and M. Shimizu: J. Chem. Eng. Japan, 7, 467 (1974).

2) Kokugan, T. and M. Shimizu: ibid., 9, 243 (1976).

3) Ramser, T. H.: Ind. Eng. Chem., 49, 155 (1957).

4) Sato, K.: "Bussei Josu suisanho", Maruzen, Tokyo (1968).

5) Yeh, H. M.: J. Chinese Inst. Chem. Eng., 1, 13 (1970).

6) Yeh, H. M. and C. S. Tsai: Chem. Eng. Sci., 27, 2063 (1972). 